\title{
Experimental Investigation of Vibration Response of a Flexible Coupler In a Four Bar Mechanism Due to Varying Crank Length and Crank Speed
}

\author{
Rizky Arman ${ }^{1, *}$, Andi Isra Mahyuddin ${ }^{2}$, Wenny Marthiana ${ }^{1}$, Iman Satria ${ }^{1}$ \\ ${ }^{1}$ Mechanical Engineering Department, Bung Hatta University, Padang, Indonesia \\ ${ }^{2}$ Mechanical Engineering Department, Bandung Institute of Technology, Bandung, Indonesia
}

\begin{abstract}
Effort to increase productivity calls for increasingly higher operating speed. Consequently, many part of a machinery are made as light as possible to avoid the detrimental inertial effects. This condition means several of the elements are no longer rigid and tend to experience elastic deformation in operation. The existence of the deformation yields element possessing position dependent dynamic parameters. Mechanisms with timevarying parameter have a phenomenon known as parametric instability where the mechanism could becomes dynamically unstable at several frequency bands, even at relatively low excitation frequency. This research investigates the dynamic behaviour of a flexible coupler on an experimental four-bar mechanism setup. The study examines the coupler vibration response due to varying crank length and crank speed.
\end{abstract}

\section{Introduction}

In engineering, dynamic analysis of machines or systems with many components, which all the components are considered rigid, it can be done easily. However, in an effort to increase the productivity, the machines with high speed are needed. Therefore, some engine components are made as light as possible so that the effect of inertia is reduced. The impact of this reduction in inertial forces resulting structure is more easily deformed.

Consequently, the stiffness of the rod that changed to the position, then the dynamic behaviours of elastic rod was governed by nonlinear partial differential equations in timevarying coefficients. One characteristic of the system that has changed the equation of motion with the coefficient of time-varying is a parametric instability that occurs in various frequency bands [1-4]. Several studies on this research had been done [5] who conducted an analysis of the shaft of the mechanism with the connecting rod and crankshaft are flexible. Mahyuddin [6] investigate by analytical and experimental dynamic response and parametric instabilities in the mechanisms Cam-Follower with a flexible shaft and Schwab [7] analysed the dynamic response of the elastic mechanism. Influence of crank length on the dynamic properties of elastic rod circuited conducted by Chen [8].

${ }^{*}$ Corresponding author: rizky.arm@gmail.com 
Theoretical investigation the influence of several parameters from the parametric instabilities of four-bar mechanism with flexible connecting rod has been done $[6,9]$. The theoretical knowledge derived through mathematical equations to investigate the parametric instability and dynamic response as a function of the change in frequency and amplitude parameters. This research aims to study the dynamic behaviours of elastic rod [10]. For that reason, a vibration response investigation using strain gage sensors employed to measure midpoint strain of elastic connecting rod on the device model test (four bar mechanism). The study conducted for a wide variety of radius $\mathrm{R}$ and rotational crank speed, $\omega$. The crank radius variations are 10 to $40 \mathrm{~mm}$ with each interval of $3 \mathrm{~mm}$, while the rotational speed variation of the crank is 180 to $1875 \mathrm{rpm}$.

\section{Material and Methods}

\subsection{Elastic Mechanism}

The elastic mechanism is defined as a mechanism that has at least one elastic component. The elastic rod will cause the mechanism can no longer be analysed as a rigid body. A general model of the elastic rod is made with the initial curvature that aims to facilitate the emergence of elastic properties that generate parametric excitation. The state equilibrium for the elastic connecting rod position before and after deflected was observed as shown as Fig. 1 [11,12].

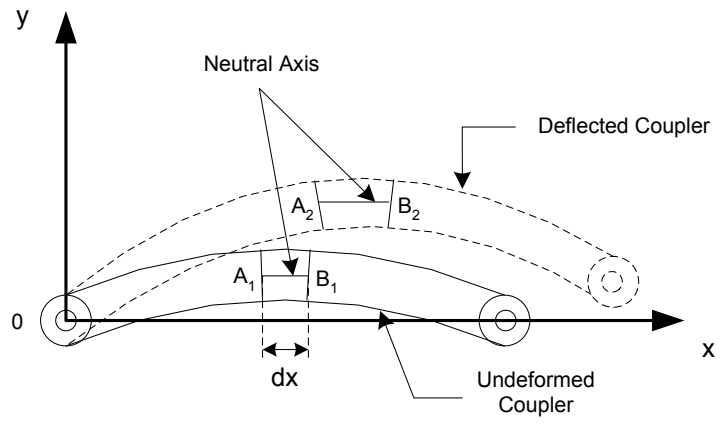

Fig. 1. Elastic rod, before and after deflected

In Fig. 2 are shown in free body diagram of $d x$ elements, where M, P and Q is the bending moment, axial force and transverse force acting on the rod. Free body diagram of $d x$ elements create equal balance of forces and moments.

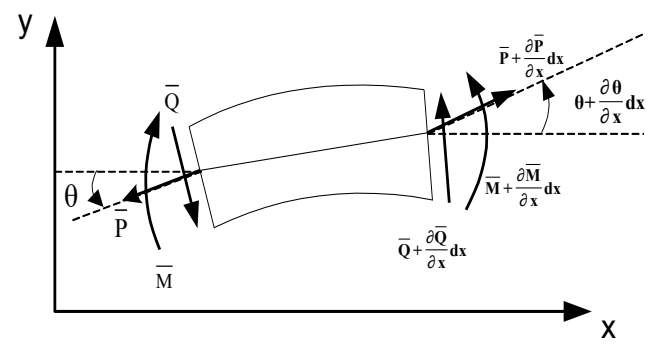

Fig. 2. Free body diagram of elastic rod 
Elastic rod can be modelled as a combined system that has stiffness and damping. The damping is assumed as a linear viscoelastic $[13,14]$. By using Kelvin-Voigt model, then the relationship of stress and strain can be obtained as

$$
\sigma_{n}=E \cdot \varepsilon_{n}+\eta \frac{\partial \varepsilon_{n}}{\partial t}
$$

\subsection{Dynamic Response and Parametric Stability of a Four Bar Mechanism}

One characteristic of the system that has the equations of motion with the time-varying coefficient is a parametric instability that can occur in a variety of frequency bands $[15,16]$. Many methods can be used to evaluate the stability of the steady-state solution, including Hill's method, perturbation and Floquet method. Hill's method is an analytical method that is difficult to apply to systems with many degrees of freedom, whereas the method Floquet is a numerical approach, which more easily applied to systems with many degrees of freedom.

Parametric instabilities that occur in several frequency bands can be represented as an unstable region in the field of amplitude-frequency parameters. Early emergence of parametric instability area is referred to as the critical frequency or frequency bifurcation that can describe as

$$
\omega=\frac{2 . \omega_{i}}{n} \quad ; \mathrm{i}=1,2, \ldots, \mathrm{k} ; \mathrm{n}=1,2, \ldots
$$

In the study conducted by Huda and Mahyuddin [6] states that the elastic rod analysis on a four bar mechanism can be obtained in the same way as on slider crank mechanism. The elastic rod Coordinates of any point of $\mathrm{T}$ in coordinates $(O X Y)$ as shown in Fig. 3, are

$$
\begin{aligned}
& X_{p}=r \cdot \cos \varphi(x+u) \cos \beta+\left(v+v_{0}\right) \sin \beta \\
& Y_{p}=r \cdot \sin \varphi(x+u) \sin \beta+\left(v+v_{0}\right) \cos \beta
\end{aligned}
$$

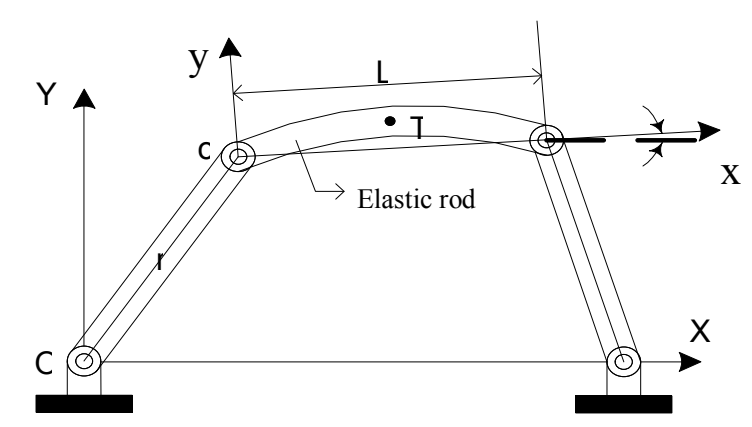

Fig. 3. Four bar mechanism

Various methods can be performed, such as using a type of filter both when doing data acquisition and data processing. The method in this research is utilizing the signal filtering on measurement devices and Matlab software for further data processing [17].

\section{Results and Discussion}

To plot the graph of strain versus time in frequency domain, the data in format.xls called up and programmed in Matlab. The graph obtained from strain versus time with a sampling 
rate of $1000 \mathrm{~Hz}$ still seemed 'rough', so it is still difficult to see the periodicity of the signal. We perform the method of data smoothing utilizing curve-fitting tool from Graphical User Interface (GUI), so that the signal curve looks more refined and periodicity can be determined. After we obtained the optimal fitting method, then it can be plotted the data of curve-fitting result as. While the data of the frequency domain and the curve-fitting result is obtained by creating a new program in Matlab command window.

From the data processing, we can determine the maximum value (peak to peak) response from strain versus time. Some examples of strain graph in a radius of 10, 25 and $40 \mathrm{~mm}(\mathrm{R} 10$, R25 and R40), and the examples of maximum strain value is presented in Table 1. From the example shown that the rotational speed crank growing on each radius of crank R10, R25 and R40 respectively, and strain response graph also being relatively more smoothly (sinusoidal).

Table 1. Some examples of maximum strain values at R10, R25 and R40 mm

\begin{tabular}{|c|c|c|}
\hline $\begin{array}{c}\text { Crank Radius, } \mathbf{R} \\
(\mathbf{m m})\end{array}$ & $\begin{array}{c}\text { Crank Speed, } \boldsymbol{\omega} \\
(\mathbf{r a d} / \mathbf{s})\end{array}$ & $\begin{array}{c}\text { Maximum Strain, } \boldsymbol{\varepsilon} \\
(\mathbf{m m} / \mathbf{m m})\end{array}$ \\
\hline \multirow{3}{*}{$\mathrm{R}=10 \mathrm{~mm}$} & 37.8 & $2.0184 \times 10^{-5}$ \\
\cline { 2 - 3 } & 84.3 & $2.5358 \times 10^{-5}$ \\
\cline { 2 - 3 } & 180.12 & $6.3560 \times 10^{-5}$ \\
\hline \multirow{3}{*}{$\mathrm{R}=25 \mathrm{~mm}$} & 39.27 & $1.3241 \times 10^{-5}$ \\
\cline { 2 - 3 } & 83.75 & $2.5664 \times 10^{-5}$ \\
\cline { 2 - 3 } & 149.54 & $1.0799 \times 10^{-4}$ \\
\hline \multirow{3}{*}{$\mathrm{R}=40 \mathrm{~mm}$} & 36.44 & $1.1921 \times 10^{-5}$ \\
\cline { 2 - 3 } & 67.54 & $3.9590 \times 10^{-5}$ \\
\cline { 2 - 3 } & 130.9 & $1.3435 \times 10^{-4}$ \\
\hline
\end{tabular}

The maximum strain value on each crank radius then plotted against variation of crank rotation speed. From the plot results, it shows the fluctuations in the value of the strain in each variation of the radius and rotational speed crank. This phenomenon is called a subharmonic resonance. The examples of sub-harmonic resonances frequency at R10, 25 and 40 mm.

Furthermore, when viewed from the frequency domain also showed that when the crank rotational speed is relatively low for each variation of the crank radius then obtained other peaks (frequencies) apart than the system frequency [18] (caused by crank speed). At relatively high rotational speed, the peak frequency from the system is more dominant and the frequency curve is "smoother".

\section{Conclusions}

Experimental investigation of vibration response of flexible coupler in a four bar mechanism show its dynamic behaviours due to crank length and crank speed. The shape of strain versus time graph is obtained from each variation of condition of parameter test. In general, the crank rotational speed is relatively low $(<1000 \mathrm{rpm})$ for each variation of the crank radius (R10 to $\mathrm{R} 40 \mathrm{~mm}$ ), the strain versus time curves tend to experience periodic in every 2 to 3 times of periods. When the crank speed is relatively high (>1000 rpm), the shape of strain versus time curve tends periodically at any one period. From the comparative analysis with slider-crank mechanism [5], also obtained the same phenomenon. 


\section{References}

1. J. A. Richards, Analysis of Periodically Time-Varying Systems. Berlin, Heidelberg, New York: Springer-Verlag, (1983).

2. W. R. Chen, Acta Mech., 216, no. 1-4, pp. 207-223, (2011).

3. Z. Jinfu, Q. Weiyang, and H. Xinsuo, "Stability Analysis Of Elastic Vibration Of Connecting Rod Of A Slider-Crank Mechanism," vol. 2, no. 1, pp. 31-40, (2006).

4. S. V. Levyakov and V. V. Kuznetsov, Acta Mech., 211 1-2, 73-87, (2010)

5. K. Farhang, "Analytical and Experimental Parametric Vibration Stability Studies in Elastic Mechanisms," Purdue University, W. Lafeyette, IN, USA, (1989).

6. A. I. Mahyuddin, "Analytical and Experimental Investigations of Dynamic Response and Parametric Instability in Flexibel Cam-Follower System," Purdue University, W. Lafeyette, IN, USA, (1993).

7. A. L. Schwab, "Dynamics of Flexible Multibody Systems; Small Vibrations Superimposed on a General Rigid Body Motion,” Delft University of Technology, Delft, The Netherlands, )2002).

8. C. Chen, J.S., Chian, ASME, J. Vib. Acoust., 123, pp. 318-323, (2001).

9. S. M. Hashemi-Dehkordi, A. R. Abu-Bakar, and M. Mailah, Adv. Mech. Eng., (2014).

10. Y. Bian, Z. Gao, and M. Fan, "A Vibration Control Method for the Flexible Arm Based on Energy Migration," vol. 2015, (2015).

11. A. Tusnin, Procedia Eng., 150,1673-1679, (2016).

12. J. P. Fuertes, O. Murillo, J. León, C. Luis, D. Salcedo, I. Puertas, and R. Luri, Procedia Eng., 132 313-318, (2015).

13. C. E. Majorana and B. Pomaro, Eng. Comput., 28, 2,. 114-129, (2011).

14. V. D. Potapov, Acta Mech., 212, 1-2. 123-129, (2010).

15. A. Talimian and G. M. V??r??s, Period. Polytech. Civ. Eng., 57, 2, 123-128, (2013).

16. A. Yildiz, O. Kopmaz, and S. T. Cetin, J. Mech. Sci. Technol., 29 3, 1001-1006, (2015).

17. D. Q. Cao and R. W. Tucker, Int. J. Solids Struct., 45 2, 460-477, (2008).

18. A. Cabboi, T. Putelat, and J. Woodhouse, J. Mech. Phys. Solids, 92 210-236, (2016). 